\title{
TREATMENTS FOR AVASCULAR NECROSIS OF THE FEMORAL HEAD USING SHORT-STEM HIP ARTHROPLASTY
}

\author{
Mai Duc Thuan*, Nguyen Quoc Dung ${ }^{\star}$, Nguyen Tung Lam*
}

\section{ABSTRACT}

Osteonecrosis of the femoral head (ONFH) develops when the bone in the head of the femur dies and gradually collapses due to the disruption of its blood supply. Total hip arthroplasty (THA) is the standard treatment for patients with latestage ONFH. However, there is uncertainty about the type of prosthesis design that provides the best outcome. During the last decade, despite the increasing number of researches on short-stem prostheses, it is still questionable whether they represents a risk factor for failure after implantation. The aim of this study was to review researches comparing the outcome of short-stem and conventional-stem arthroplasty in ONFH and to present the pros and cons of short-stem hip arthroplasty in osteonecrosis of the femoral head. The short- to medium-term results showed predominantly good outcomes. However, due to differences in the design of short stems and their fixation, it is hard to draw a general conclusion. Short stems with primary diaphyseal fixation do not reveal a high increased risk of failed integration or loosening. For designs with a primary metaphyseal anchorage, an MRI should be conducted to exclude that the necrosis exceeds the femoral neck.

Keywords: Osteonecrosis of the femoral head, short-stem arthroplasty, total hip arthroplasty

\section{INTRODUCTION}

Osteonecrosis of the femoral head (ONFH) develops when the bone in the head of the femur dies and gradually collapses due

*108 Military Central Hospital

Responsible person: Mai Duc Thuan

Email: thuanmd108@gmail.com

Date of receipt: 01/7/2021

Date of scientific judgment: 31/7/2021

Reviewed date: 19/8/2021 to the disruption of its blood supply. ONFH typically occurs in patients between the ages of 30 and 60 years. Trauma, smoking, excessive alcohol consumption, infections, hyperbaric events, lipid metabolic disorder, coagulation defects, corticosteroid intake and genetic mutation of the type II collagen have been associated with ONFH [1]. Without treatment, ONFH would likely results in subchondral fracture, leading to femoral head collapse and secondary osteoarthritis.[1]. Mont et al. presented a systematic review of untreated asymptomatic ONFH and revealed $49 \%$ progression to collapse of the femoral head after 49 months [1].

There are many classification systems that describe the clinical and radiological stages of ONFH. The Ficat and Arlet-staging system is still one of the most commonly used systems [Table 2]. It is based on radiological findings, but does not consider the extent of necrosis. Steinberg et al added quantification of femoral head involvement to the classification system. Accordingly, the treatment can be broadly categorized into two types; treatment in the precollapsed or early collapsed stage $<2 \mathrm{~mm}$ and treatment after advanced collapse or osteoarthritis of hip joint.

In the post-collapse stage, although there are many joint-preserving techniques, their outcome has been poor. Core decompression revealed success rates of only 21-35\%. Vascularized fibular grafts had a low survival rate of $64.5 \%$ after a mean follow-up of 4.3 years [2], [3]. Similarly, about $25 \%$ of 
patients with intertrochanteric and rotational transtrochanteric osteotomies had to convert to total hip arthroplasty after 5 years [4].

On the other hand, total hip arthroplasty (THA) stood out and became the only predictable effective treatment of $\mathrm{ONFH}$ once the disease process has reached advanced collapse or osteoarthritis of hip joint.

The younger age of patients with ONFH have led to new developments in implant designs: the short-stem prosthesis. These stems could preserve more native host bone and optimize proximal load transfer. The aim of this review is to outline the pros and cons of short-stem arthroplasty in advanced ONFH according to existing literature.

\section{MATERIALS AND METHODS}

A systemic literature review was conducted using the PubMed database. "Short stem" and ("Osteonecrosis of the femoral head" or "avascular necrosis") were the keywords for the first literature search. A second literature search was conducted amongst the references of above articles. The literature found was further reviewed to select the studies that analysed the outcome of short-stem arthroplasty in patients with ONFH. Inclusion criteria were: outcome of patients after THA due to the underlying diagnosis "osteonecrosis of the femoral head" and analysing the outcome after implantation of a short- stem arthroplasty.

The selected papers were analysed for outcome and complication rate.

\section{RESULTS}

The first search within the PubMed database using "Short stem" and ("Osteonecrosis of the femoral head" or "avascular necrosis") detected fifty six (56) papers, amongst those fourteen met the inclusion criteria. The second search found two additional papers.

These manuscripts were reviewed to select only those that presented the results of short-stem arthroplasty in patients with ONFH. This selection yielded seven papers.

The results of the different papers are presented in Table 1.

Table 1: Overview of the existing literature regarding the post-implantation outcome of shortstem total hip arthroplasty in patients with osteonecrosis of the femoral head

\begin{tabular}{|l|l|c|c|c|c|}
\hline $\begin{array}{c}\text { Author/ } \\
\text { Time }\end{array}$ & \multicolumn{1}{|c|}{ Title } & $\begin{array}{c}\text { Number } \\
\text { of hips } \\
\text { and } \\
\text { patients }\end{array}$ & $\begin{array}{c}\text { Type of } \\
\text { stem } \\
\text { (company) }\end{array}$ & $\begin{array}{c}\text { Follow } \\
\text {-up }\end{array}$ & $\begin{array}{c}\text { Results (preoperativ - } \\
\text { Follow up) }\end{array}$ \\
\hline $\begin{array}{l}\text { Fink } \\
(2012)\end{array}$ & $\begin{array}{l}\text { The thrust plate } \\
\text { prosthesis in } \\
\text { patients with } \\
\text { aseptic } \\
\text { osteonecrosis of } \\
\text { the femoral head. }\end{array}$ & $\begin{array}{c}72 \text { hips in } \\
63 \\
\text { patients } \\
\text { Thrust } \\
\text { plate } \\
\text { prothesis }\end{array}$ & Zimmer & $\begin{array}{l}4.8 \\
\text { years }\end{array}$ & $\begin{array}{l}\text { HHS: 50-86.8 six revisions: 3 } \\
\text { aseptic loosenings, 3 septic } \\
\text { loosenings }\end{array}$ \\
\hline
\end{tabular}


VIETNAM MEDIGAL JOURNAL $N^{\circ} 1 \& 2 / 2021$

\begin{tabular}{|c|c|c|c|c|c|}
\hline $\begin{array}{l}\text { Jerosch } \\
\text { (2014) }\end{array}$ & $\begin{array}{l}\text { [Is there an } \\
\text { indication for a } \\
\text { partial neck } \\
\text { preserving short } \\
\text { stem (Mini hip) in } \\
\text { patients with an } \\
\text { avascular necrosis } \\
\text { of the femoral } \\
\text { head?] }\end{array}$ & $\begin{array}{l}20 \text { hips in } \\
18 \\
\text { patients }\end{array}$ & $\begin{array}{l}\text { Mini hip } \\
\text { (Corin) }\end{array}$ & 4 years & $\begin{array}{l}\text { HOOS: 44.4-96.2; OHS: } 24- \\
\text { 47.1; no complication }\end{array}$ \\
\hline $\begin{array}{l}\text { Kim } \\
(2012)\end{array}$ & $\begin{array}{l}\text { A Prospective } \\
\text { Short-Term } \\
\text { Outcome Study of } \\
\text { a Short } \\
\text { Metaphyseal } \\
\text { Fitting Total Hip } \\
\text { Arthroplasty }\end{array}$ & $\begin{array}{c}88 \text { hips of } \\
144 \\
\text { patients }\end{array}$ & $\begin{array}{l}\text { Proxima } \\
\text { (Depuy) }\end{array}$ & $\begin{array}{c}4.5 \\
\text { years }\end{array}$ & HHS: 45-96 WOMAC: 63-11 \\
\hline $\begin{array}{l}\text { Yasunaga } \\
\text { (2012) }\end{array}$ & $\begin{array}{l}\text { Clinical and } \\
\text { radiographical } \\
\text { results of } 179 \\
\text { thrust plate hip } \\
\text { prostheses: 5-14 } \\
\text { years follow- up } \\
\text { study }\end{array}$ & $\begin{array}{c}92 \text { hips in } \\
79 \\
\text { patients }\end{array}$ & $\begin{array}{l}\text { Thrust } \\
\text { plaste } \\
\text { prosthesis } \\
\text { (Zimmer) }\end{array}$ & $\begin{array}{c}65 \\
\text { months }\end{array}$ & $\begin{array}{l}\text { Merle d'Aubigne's score: 9.1- } \\
16.6 \\
1 \text { mechanical loosening } \\
1 \text { patient with bilateral } \\
\text { infected hips } \\
2 \text { patients with spontaneous } \\
\text { femoral fracture below the tip } \\
\text { of the lateral plate Kaplan- } \\
\text { Meier suvivorship: } 90.3 \%\end{array}$ \\
\hline
\end{tabular}

Table 2: Overview of the existing literature regarding the post-implantation outcome of standard stem total hip arthroplasty in patients with osteonecrosis of the femoral head

\begin{tabular}{|c|c|c|c|}
\hline $\begin{array}{l}\text { Author } \\
\text { /Time }\end{array}$ & Title & $\begin{array}{c}\text { Number of hips } \\
\text { and patients }\end{array}$ & Results / Conclusion \\
\hline $\begin{array}{l}\text { Babis } \\
(2004)\end{array}$ & $\begin{array}{l}\text { Effectiveness of total hip } \\
\text { arthroplasty in } \\
\text { management of hip } \\
\text { osteonecrosis }\end{array}$ & & $\begin{array}{l}\text { THA initially showed universally bad } \\
\text { results when performed in ONFH. } \\
\text { Newer techniques and implants } \\
\text { remarkably improved these results. } \\
\text { THA even in ONFH is proven to be } \\
\text { safe and effective and to have } \\
\text { survivorship similar to cases with } \\
\text { osteoarthritis. }\end{array}$ \\
\hline $\begin{array}{l}\text { Bergh } \\
(2014)\end{array}$ & $\begin{array}{l}\text { Increased risk of revision } \\
\text { in patients with non- } \\
\text { traumatic femoral head } \\
\text { necrosis }\end{array}$ & $\begin{array}{lr}427,806 & \text { THAs } \\
\text { performed between } \\
1995 \text { and } 2011 \text { were } \\
\text { included from the } \\
\text { Nordic Arthroplasty } \\
\text { Register Association }\end{array}$ & $\begin{array}{l}\text { Patients with ONFH had an overall } \\
\text { increased risk of revision. The } 16- \\
\text { year survival in the } 2 \text { groups was } 86 \\
\% \text { for primary osteoarthritis and } 77 \\
\%\end{array}$ \\
\hline $\begin{array}{l}\text { Hartley } \\
\text { (2014) }\end{array}$ & $\begin{array}{l}\text { Osteonecrosis of the } \\
\text { femoral head treated } \\
\text { with cementless total hip } \\
\text { arthroplasty }\end{array}$ & $\begin{array}{l}55 \text { hips in } 45 \text { patients } \\
\text { with ONFH }\end{array}$ & $\begin{array}{l}\text { No revision due to aseptic loosening } \\
\text { of the femoral component- } \\
\text { Cementless total hip arthroplasty } \\
\text { remains a reasonable treatment } \\
\text { option for advanced osteonecrosis } \\
\text { of the femoral head. }\end{array}$ \\
\hline
\end{tabular}


№1\&2/2021 VIETNAM MEDICAL JOURNAL

\begin{tabular}{|c|c|c|c|}
\hline $\begin{array}{l}\text { Ince } \\
(2006)\end{array}$ & $\begin{array}{l}\text { No increased stem } \\
\text { subsidence } \\
\text { arthroplasty in young } \\
\text { patients with femoral } \\
\text { head osteonecrosis: } 41 \\
\text { patients followed for } 1-9 \\
\text { years }\end{array}$ & $\begin{array}{l}41 \text { hips in patients } \\
\text { with ONFH }\end{array}$ & $\begin{array}{l}\text { There was no revision of any hip. } \\
\text { After } 60 \text { months, the cementless } \\
\text { stems showed a median subsidence } \\
\text { of }-0.7 \mathrm{~mm} \text {. }\end{array}$ \\
\hline $\begin{array}{l}\text { Johannso } \\
\text { n } \\
(2011)\end{array}$ & $\begin{array}{l}\text { Osteonecrosis is not a } \\
\text { predictor of poor } \\
\text { outcomes in primary total } \\
\text { hip arthroplasty: a } \\
\text { systematic literatur } \\
\text { review }\end{array}$ & $\begin{array}{l}\text { Systematic literature } \\
\text { review of } 67 \text { reports } \\
\text { representing } 3,277 \\
\text { hips in 2,593 patients } \\
\text { with THA due to } \\
\text { ONFH }\end{array}$ & $\begin{array}{l}\text { Significant decrease in revision } \\
\text { rates between patients operated } \\
\text { upon before } 1990 \text { versus those } \\
1990 \text { or later, with rates of } 17 \% \\
\text { and } 3 \% \text {, respectively }\end{array}$ \\
\hline $\begin{array}{l}\text { Stavraki } \\
(2014)\end{array}$ & $\begin{array}{l}\text { A comparison of the } \\
\text { incidence } \\
\text { complications following } \\
\text { total hip arthroplasty in } \\
\text { patients with and without } \\
\text { osteonecrosis }\end{array}$ & $\begin{array}{lr}\text { Statewide } & \text { hospital } \\
\text { admission r } & \text { was } \\
\text { identified } & (1995-2010)\end{array}$ & $\begin{array}{l}\text { Osteonecrosis led to an increased } \\
\text { risk of sepsis and readmission } \\
\text { without difference in mortality rate }\end{array}$ \\
\hline $\begin{array}{l}\text { Wang } \\
\text { (2013) }\end{array}$ & $\begin{array}{l}\text { Noncemented total hip } \\
\text { arthroplasty } \\
\text { osteonecrosis of tor } \\
\text { femoral head in elderly } \\
\text { patients }\end{array}$ & $\begin{array}{l}107 \text { hips in } 103 \\
\text { patients with ONFH }\end{array}$ & $\begin{array}{l}\text { Survivorship of prosthesis was } \\
95 \%(88 / 92) \text { with minimal 5-year } \\
\text { follow-up. Noncemented THA was } \\
\text { effective in the treatment of ONFH } \\
\text { in this group of patients }\end{array}$ \\
\hline $\begin{array}{l}\text { Xenakis } \\
(2001)\end{array}$ & $\begin{array}{l}\text { Cementless } \\
\text { arthroplasty in the } \\
\text { treatment of patients } \\
\text { with femoral head } \\
\text { necrosis }\end{array}$ & $\begin{array}{l}36 \text { cementless hips in } \\
28 \text { patients with ONFH }\end{array}$ & $\begin{array}{l}\text { Survival rate of } 93.4 \% \text { at the } \\
\text { average followup of } 11.2 \text { years }\end{array}$ \\
\hline
\end{tabular}

\section{DISCUSSION}

Earlier findings revealed a suboptimal outcome of standard THA in patients with ONFH compared to patients with primary osteoarthritis. However, recent publications have disproved these previous findings and revealed an equally good outcome of THA after ONFH and after osteoarthritis. Different reasons for these discrep- ancies were described in the research literature. They include the use of first-generation prosthetic designs in the early studies and the fact that underlying risk factors as- sociated with the individual patients were not considered.

Initially, several studies showed poor results of THA in osteonecrosis treatment with a high failure rate. These are due to relative young patients, long life expectancy, inferior bone quality with different tissue response. Nowadays, outcomes are improved thanks to better implant, bearings, component design, improved materials and cementing technique. There was a significant decrease in revision rates between patients operated upon before 1990 versus those in 1990 or later, with rates of $17 \%$ and $3 \%$, respectively.

\section{Lack of a superior THA in ONFH}

There is a lack of consensus in the literature about the most appropriate arthroplasty method for patients with progressive ONFH. The different options include hemiarthroplasty, hip resurfacing, long-stem arthroplasties or recently shortstem arthroplasties [5, 6, 7, 8]. 
The number of different treatment options already indicates a lack of a superior procedure in patients with progressive ONFH. Confusion about the best treatment option is due to the conflicting reports about the outcome of the individual procedures in the literature and the lack of studies with long-term results about short-stem THAs and the latest prosthetic designs. An optimal arthroplasty treatment for progressive ONFH would provide pain relief and allow the patient to resume physical activities [7]. Due to the frequent young age of patients with ONFH, the THA would ideally preserve bone mass as well to allow more options if revision is needed in the future.

During the last decade, the number of cementless, short- stem THAs has increased. There are various reasons for this. The implantation of short-stem THAs enables further options for revision with implantation of a standard THA in the event of loosening due to a higher resection height and a different fixation pattern. Similar options for revision also exist for hip resurfacing. However, at present, the majority of surgeons prefer the implantation of a short-stem THA in young patients.

July 2004 THA initially showed universally bad results when performed in ONFH. Newer techniques and implants remarkably improved these results. THA even in ONFH is proven to be safe and effective and to have survivorship similar to cases with osteoarthritis.

Patients with ONFH had an overall increased risk of revision. The 16-year survival in the 2 groups was $86 \%$ for primary osteoarthritis and $77 \%$ for ONFH. The overall revision rate for cemented and hybrid hips at 2 to 10 years followup was $4 \%$. Worst-case survivorship was $58.1 \%$ at 13 years and best-case was $93.3 \%$

No revision due to aseptic loosening of the femoral component. Cementless total hip arthroplasty remains a reasonable treatment option for advanced osteonecrosis of the femoral head. There was no revision of any hip. After 60 months, the cementless stems showed a median subsidence of -0.7 $\mathrm{mm}$.Significant decrease in revision rates between patients operated upon before 1990 versus those in 1990 or later, with rates of 17 $\%$ and $3 \%$, respectively

Survival rate of $79.5 \%$ at the average followup of 7.2 years. The cementless total hip arthroplasty in this series had a higher incidence of aseptic loosening of the femoral component, polyethylene liner wear, and periprosthetic osteolysis than that reported for cemented total hip arthroplasty using contemporary techniques.

Patients with osteonecrosis who are younger than 50 years have a significantly higher rate of mechanical failure than those with osteoarthritis who are younger than 50 years.

\section{Supposed benefits of short-stem THA}

In the meantime, a range of short-stem designs has been introduced into the market. The Mayo stem was a pioneer of short-stem THAs. However, the different designs seem to induce different load bearings. These short stems can be distinguished into different categories. One classification is published according to the resection height: neck contain- ing (e.g. CUT ), partial neck containing (Mayo , METHA, Nanos ,) and neck resection designs. The latter can be differentiated into short long-term 
arthroplasties (e.g. Taperloc microplasty) or proximal fitting anatomic stems (e.g. Proxima). Neck containing stems induce a metaphyseal anchorage. However, it is primarily suitable for physiological anatomy. Partial neck containing stems induce a primary metaphyseal anchorage. The tip of these stems helps stabilise the implant during osseointegration of the lateral cortex. The group of neck resection implants represent mainly shortened standard stems with diaphyseal anchorage. A possible benefit of the femoral neck retaining and partial retaining THAs is the supposed greater physiological load bearing with a more proximal fixation compared to standard THA. A greater physiological load bearing of these THAs is supposed to reduce stress shielding and consequently reduce aseptic loosening. However, biomechanical testing or DXA analysis is nec- essary to prove the supposed greater physiological load bearing for the different designs. So far only DXA analysis of the METHA has revealed a mainly metaphyseal fixation [9]. A possible disadvantage of femoral neck re- taining or partial retaining designs is that these need to have a good bone quality within the femoral neck to avoid the risk of missing osseointegration, as the surface is smaller compared to one of conventional stems. However, the majority of short stems reveal a greater diameter in the proximal part, which increases the rotational stability.

Minor bone quality in the femoral neck in ONFH?

A metaphyseal fixation may be considered crucial in pa- tients with ONFH. Opponents of short-stem THAs argue that a metaphyseal anchorage may be associated with an increased risk of subsidence due to inferior bone quality within the metaphysis. This minor quality may occur when the necrotic area exceeds the femoral head in patients with ONFH. There is histological evidence that ONFH may involve not only the intracapital region but also the femoral neck and metaphyseal area, which may result in a higher rate of aseptic loosening. Tingart et al. analysed the bone matrix composition and trabecular microarchitecture of the femoral metaphysis in patients with ONFH [6]. They determined altered trabecular properties in ONFH bone for bone volume (OA: $32 \mathrm{~mm}^{3}$, ONFH: $51 \mathrm{~mm}^{3}$ ) and structure model index (OA: 2.2, ONFH: 1.6) in the prox- imal femoral canal, but not in the trochanteric regions. They concluded that these alterations in bone metabolism and architecture might contribute to the higher rates of stem loosening after total hip replacement in patients with ONFH. However, Tingart et al. added the necessity of further experimental and clinical studies to support these findings. Furthermore, Koo et al. determined an increased ratio of fatty marrow conversion of the proximal femoral metaphysis of the greater trochanter using MRI analysis in patients with ONFH compared to the group of osteoarthritis. Fink et al. analysed the outcome of the thrust plate prosthesis in ONFH and determined an extension of the necrotic area into the femoral neck as a contraindication for the implantation of the thrust plate prosthesis [7]. Braun et al. recommend the use of the METHA short stem for THA when the femoral bone quality and morphology support the metaphyseal anchoring concept. 
Although increasing clinical experience reveals that the indication can be extended, adequate studies are needed to support the possible extension of the indication for shortstem THA, also for ONFH. However, when implanting a short-stem THA-like Nanos, METHA or Proxima- correctly, the cancellous bone should be removed so that the stem is located within the cortical bone. The necrotic area, which is located within the cancellous bone, should there- fore be completely removed so that ONFH does not nec- essarily outline a contraindication. Furthermore, previous studies revealed good survivorships of uncemented stems even in osteoporotic bone. Moritz et al. analysed local bone quality by structural ICT imaging and destructive compression testing. The resulting data were used as a predictor of three-dimensional stem migration determined by radiostereometric analysis up to 24 months. They con- cluded that poor quality of intertrochanteric cancellous bone seems to contribute to the risk of implant migration less than expected. The importance of surgical preservation of in- tertrochanteric cancellous bone has probably been overemphasised for osseointegration of cementless stem. Meding et al. also analysed the influence of osteoporotic bone on aseptic loosening after implanting proximally plasma-sprayed, straight-stemmed titanium alloy stems in

1994 patients (2321 hips). They identified no differences in Harris hip scores, pain, radiolucencies, or osteolysis among osteoporosis classes A, B, and C hips. Stem survival at 5,10 , and 15 years was $100 \%$ in all patients with class A bone, $99 \%$ in class $\mathrm{B}$ bone and $100 \%$ in class $\mathrm{C}$ bone. Therefore, it is concluded that initial stability and durable fixation can be achieved with the use of this uncemented stem in patients in whom a cemented stem has been traditionally preferred due to poor bone quality.

\section{Outcome of short-stem THA in ONFH?}

Only a handful of studies present results of short-stem arthroplasties in patients with progressive ONFH [7]. Zeh et al. analysed the medium-term results of the Mayo shortstem prosthesis after $\mathrm{ON}$ with particular attention to osseointegration. After implantation of 26 Mayo short-stem THAs in 21 patients with ONFH, longitudinal stem migration and varus-valgus femoral stem alignment were examined. In addition, the incidence of periprosthetic radiolucent lines was captured in antero-posterior X-rays and assigned to the Gruen zones, and a DEXA scan was also performed. The authors revealed no increased migration or tilt for Mayo short-stem THA in patients with ONFH. Based on their results, they concluded that the Mayo conservative hip is an alternative for operative treatment of ONFH. These results can be confirmed by clinical and radiological follow-up after implantation of the METHA short stem. The outcome of the METHA short-stem arthroplasty in 74 hips of 64 patients with ONFH showed an increase of the HHS from 37.7 preop- eratively to 89.3 points after a mean follow-up of 34 months. Complications associated with revision of the short stem included two traumatic femoral shaft fractures and one deep infection. The radiological assessment showed good osseointegration in all patients despite ONFH. Furthermore, Braun and Sabah reported of a HHS of 95 points in a group of 48 patients at a follow-up of 2.4 years after implantation of the METHA short-stem arthroplasty due to primary or secondary coxarthrosis. In $13 \%$ of the patients, the indication for implantation of a THA was given due to ONFH. They performed one 
revi- sion due to periprosthetic fracture and one due to breakage of the cone adapter. In one patient, radiological assessment showed an aseptic loosening. Braun and Sabah also recognised a subsidence of $2 \mathrm{~mm}$ with secondary osseointegration in seven patients. A further differentiation regarding the preoperative disease is missing. Inferior results were presented by Fink et al. who analysed the out- come of 72 thrust plate prostheses in 63 patients with ONFH [7]. The Harris Hip Score increased continuously from 50.0 points beyond 79.8 points after 3 months, re- spectively, to 86.8 points within

Within this first year of follow-up, no revision was nec- essary. The thrust plate prosthesis was therefore considered to be particularly suitable for patients with ONFH. Similar results were presented by Yasunaga et al. who analysed 31 thrust plate prostheses in 27 patients with ONFH. Mechanical loosening developed about 1 year postoperatively in one joint with a bone defect. Grade 1 stress shielding was observed in four joints. Summarising the outcome of studies analysing thrust plate protheses, ONFH does not represent a risk factor for mechanical failure during implantation of thrust plate prosthesis. It is ques- tionable whether the results of the thrust plate prosthesis can be transferred to other short-stem THAs because of a different fixation concept.

Recently, Jerosch et al. presented data of the short-stem arthroplasty MiniHip. They revealed good clinical and radiological results. No complication occurred during the follow-up. Therefore, this study also revealed good out- come of a partial femoral neck containing design. In order to judge the results of short stem THAs, in Table 2 existing literature of standard stem THA are presented (Table 2). the first year, and subse- quently remained stable at this level. Revision was necessary in six cases $(8.3 \%)$. Of these, three had an aseptic loosening of the implant. The authors concluded that ONFH following renal transplantation and extension of the necrotic area into the femoral neck are contraindications for the implantation of the thrust plate prosthesis. A similar study conducted by Karatsun et al. reviewed 19 cementless thrust plate prostheses in 15 patients with ONFH. The Harris hip score increased from 53 (range 15-71) to $97(92-100)$ points 12 months postoperatively.

\section{CONCLUSION}

The treatment of ONFH continues to be a challenging problem in orthopaedics. Existing literature proved that standard stems represent a good treatment option for progressive ONFH. However, only a handful of published studies have analysed the outcome of short-stem THA in ONFH. Existing studies that presenting clinical and radiological outcome after implantation of a short-stem arthroplasty in patients with the underlying diagnosis of ONFH revealed predominantly good short- to medium- term outcomes. They show hints of good bone integration of cementless short-stem THAs without increased risk of early loosening. Nevertheless, in the case of ONFH, an MRI should exclude an enlargement of the ONFH into the femoral neck especially for femoral neck retaining and partial retaining stems. As the number of studies presenting clinical and radiological outcome after implantation of short-stem arthroplasty in patients with ONFH is low, pa- tients should be informed about the missing long-term re- sults of short-stem THAs in ONFH. 


\section{REFERENCES}

1. Mont MA, Zywiel MG, Marker DR, McGrath MS, Delanois RE (2010) The natural history of untreated asymptomatic 2. Lee osteonecrosis of the femoral head: a systematic literature review. J Bone Joint Surg Am 92(12):2165

2. Berend KR, Gunneson EE, Urbaniak JR (2003): Free vascular- ized fibular grafting for the treatment of postcollapse os- teonecrosis of the femoral head. J Bone Joint Surg Am 85-A(6):987

3. Kim SY, Kim YG, Kim PT, Ihn JC, Cho BC, Koo KH (2005) Vascularized compared with non-vascularized fibular grafts for large osteonecrotic lesions of the femoral head. J Bone Joint Surg Am 87(9):2012

4. Von Salis-Soglio Freiherr, Ruff C (1988) Idiopathic femur head necrosis in the adultresults of surgical therapy. Z Orthop Ihre Grenzgeb 126(5):492

5. Banerjee S, Pivec R, Issa K, Harwin SF, Mont MA, Khanuja HS (2013) Outcomes of short stems in total hip arthroplasty. Orthopedics 36(9):700
6. Tingart M, Beckmann J, Opolka A, Matsuura M, Schaumburger J, Grifka J, Grassel S (2009) Analysis of bone matrix composition and trabecular microarchitecture of the femoral metaphysis in patients with osteonecrosis of the femoral head. J Orthop Res 27(9):1175

7. Fink B, Schneider T, Conrad S, Jaeger M, Protzen M, Ruther W (2002) The thrust plate prosthesis in patients with aseptic osteonecrosis of the femoral head. Arch Orthop Trauma Surg 122(9-10):499

8. Mont MA, Seyler TM, Marker DR, Marulanda GA, Delanois RE (2006) Use of metal-on-metal total hip resurfacing for the treatment of osteonecrosis of the femoral head. J Bone Joint Surg Am 88(Suppl 3):90

9. Lerch M, von den Haar-Tren Windhagen H, Behrens BA, Wef- staedt P, StukenborgColsman CM (2012) Bone remodelling around the Metha short stem in total hip arthroplasty: a prospective dual-energy X-ray absorptiometry study. Int Orthop 36(3):533 